\title{
Pre-pregnancy BMI, gestational weight gain and body image are associated with dietary under-reporting in pregnant Japanese women
}

\author{
Mie Shiraishi ${ }^{1}{ }^{*}$, Megumi Haruna ${ }^{2}$, Masayo Matsuzaki ${ }^{1}$, Ryoko Murayama ${ }^{3}$ and Satoshi Sasaki ${ }^{4}$ \\ ${ }^{1}$ Children and Women's Health, Osaka University, Osaka, Japan \\ ${ }^{2}$ Midwifery and Women's Health, The University of Tokyo, Tokyo, Japan \\ ${ }^{3}$ Advanced Nursing Technology, The University of Tokyo, Tokyo, Japan \\ ${ }^{4}$ Social and Preventive Epidemiology, The University of Tokyo, Tokyo, Japan
}

(Received 18 September 2017 - Final revision received 18 January 2018 - Accepted 2 February 2018)

Journal of Nutritional Science (2018), vol. 7, e12, page 1 of 10

doi:10.1017/jns.2018.3

Abstract

Dietary under-reporting is a common problem when using self-reported dietary assessment tools. However, there are few studies regarding under-reporting during pregnancy. This study aimed to explore the demographic and psychosocial characteristics related to dietary under-reporting in pregnant Japanese women. A cross-sectional study was conducted between 2010 and 2011 at a university hospital in Tokyo, Japan. Nutrient intake was assessed using a selfadministered Diet History Questionnaire (DHQ), which had questions about the consumption frequency and portion size of selected food items. The 24-h urinary excretion levels of urea $\mathrm{N}$ and $\mathrm{K}$ were used as the dietary protein and $\mathrm{K}$ intake reference values, respectively. Under-reporting of protein and $\mathrm{K}$ was defined as the bottom $25 \%$ of the reporting accuracy (the ratio of reported intake on the DHQ to the estimated intake based on urinary excretion). Underreporters were defined as participants who under-reported both protein and $\mathrm{K}$ intake. Multiple logistic regression analysis was performed to examine the factors associated with under-reporters. Of 271 healthy women at 19-23 weeks of gestation, thirty-five participants $(12.9 \%)$ were identified as under-reporters. Under-reporters had a lower pre-pregnancy BMI (adjusted OR $(\mathrm{AOR})=0 \cdot 81$ ) and lower gestational weight gain $(\mathrm{AOR}=0 \cdot 82)$; they also reported managing their gestational weight gain with the aim to return to their pre-pregnancy weight soon after childbirth (AOR $=2.99)$. Healthcare professionals should consider the potential for dietary under-reporting and the possible related factors when assessing the dietary intakes of pregnant Japanese women using self-administered questionnaires.

Key words: BMI: Dietary under-reporting: Gestational weight gain: Pregnancy: Dietary surveys: Nutritional epidemiology

Self-reported dietary assessment tools have systematic measurement errors. A common measurement error is underreporting, which occurs especially in women ${ }^{(1,2)}$. Dietary under-reporting is a significant problem that could lead to erroneous conclusions regarding diet-disease associations ${ }^{(3)}$. In the clinical setting, dietary under-reporting may lead to incorrect assessment and instructions by healthcare professionals. Since appropriate nutrition during the prenatal period is important for fetal development and prevention of pregnancy complications, provision of incorrect nutrition-related instruction can negatively affect fetal and maternal health. Three studies on pregnant women, conducted in Indonesia, Ireland and USA, indicated that $14-44 \%$ of the women were dietary underreporters, based on the ratio of energy intake to the estimated $\mathrm{BMR}^{(4-6)}$. In non-pregnant women, the prevalence of dietary under-reporting via FFQ ranges from 12 to $54 \%{ }^{(7-16)}$. In Japan, 18-32\% of non-pregnant women have been found to under-report dietary intake $e^{(13-16)}$.

Abbreviations: DHQ, Diet History Questionnaire; FHLC, Fetal Health Locus of Control Scale; GSES, General Self-Efficacy Scale.

* Corresponding author: Mie Shiraishi, email mi-shi@umin.ac.jp 
Since the reporting accuracy of dietary intake varies according to the demographic and psychosocial characteristics of the respondents, researchers need to understand the potential risk and the related factors of under-reporting in their specific target population. The following factors related to underreporting have been identified in non-pregnant populations: demographic factors (sex and age) ${ }^{(1)}$, socio-economic factors (household income and educational level) ${ }^{(17-19)}$, dietary restrictions (previous and current) ${ }^{(8)}$, weight-related factors (BMI and body image) $)^{(1,13,16,20,21)}$ and psychosocial factors (social desirability, social approval motivation and self-efficacy) ${ }^{(2,11,22,23)}$. Previous studies on pregnant women showed that high BMI and low education levels were associated with dietary under-reporting ${ }^{(4-6)}$; however, a detailed examination including behavioural and psychological factors has not been conducted in this population. Further, these related factors vary depending on the target population or country; some factors related to under-reporting in pregnant women may not exist in non-pregnant populations.

The attitudes of pregnant women regarding diet for themselves and their babies may be easily changed. Their attitudes toward diet are often affected by particular factors associated with pregnancy, such as pregnancy-associated nausea, weight management and beliefs pertaining to the health of their babies ${ }^{(24,25)}$. In Japan, many pregnant women are careful not to gain excessive weight during pregnancy ${ }^{(25)}$ because they know that it may lead to pregnancy complications, difficult deliveries and postpartum weight retention. However, such attitudes toward weight gain during pregnancy might also influence dietary reporting accuracy, as has been reported regarding attitudes toward weight reduction in non-pregnant populations $^{(1)}$. In addition, a strong belief that maternal health behaviour has a positive effect on the well-being of babies might influence the reporting accuracies due to socially desirable responses. Identifying the factors related to underreporting during pregnancy is important in yielding reliable data for dietary research because non-random dietary underreporting could distort diet-disease associations.

The self-administered Diet History Questionnaire (DHQ) is the only dietary assessment tool that has been validated among pregnant Japanese women ${ }^{(26)}$. In order to use the DHQ appropriately, it is necessary to gain a better understanding of the reporting accuracy and factors related to underreporting during pregnancy.

For identification of under-reporters, energy expenditure is commonly measured as a reference value of the energy intake estimated from dietary assessment tools. The doubly-labelled water method is a 'gold standard' method used to measure energy expenditure ${ }^{(27)}$, and the BMR, which is calculated from the individual's weight, height and age, is often used to evaluate energy expenditure. However, these methods cannot be used in pregnant women due to unverified safety and the difficulty of estimating energy expenditure based on weight ${ }^{(28)}$. As a reference for evaluating the reporting accuracy of energy intake, the reporting accuracies of protein and $\mathrm{K}$ intakes are often evaluated using 24 -h urine collection ${ }^{(29,30)}$. This method has two advantages: protein and $\mathrm{K}$ can reflect a wide variety of foods, and 24-h urine collection is a method with comparatively few burdens compared with the doubly-labelled water method. Thus, measurement of 24-h urine markers of protein (urea $\mathrm{N}$ ) and $\mathrm{K}$ is an appropriate method to identify dietary under-reporting during pregnancy.

The objective of the present study was to examine the factors related to dietary under-reporting in the DHQ among pregnant Japanese women, using 24-h urine markers.

\section{Methods}

\section{Overview of the recruitment process and study design}

A cross-sectional study was conducted at a university hospital in Tokyo, Japan, between June 2010 and June 2011. Healthy Japanese women with singleton pregnancies, who were aged 20 years or older, and who had adequate Japanese literacy skills, were recruited at 15-19 weeks of gestation. Women who provided written informed consent participated in the investigation at 19-23 weeks of gestation. In Japan, nutritional guidance for increased nutrient needs during pregnancy is often performed around 20 weeks of gestation after nausea and vomiting are relieved. Because conducting appropriate nutritional assessment at this period is important for ensuring appropriate individual dietary instructions, we set 19-23 weeks of gestation as the target period of this investigation. The reason for recruitment at 15-19 weeks of gestation was to allow time for giving detailed instructions on the method of urine collection and provide all necessities before the investigation. The exclusion criteria included women with diseases that affected dietary intake, such as hyperemesis, diabetes and hypertension. In addition, women with psychiatric disorders such as depression and schizophrenia were excluded.

Upon recruitment (15-19 weeks of gestation), the participants received written and verbal instructions on the method of urine collection and the necessity of obtaining a complete 24-h urine collection. The participants were provided with 3 litre, 1 litre and $50 \mathrm{ml}$ plastic bottles, as well as $350 \mathrm{ml}$ cups and a dropper. A 24-h urine collection was conducted on the preceding day or within $5 \mathrm{~d}$ before the next pregnancy check-up (19-23 weeks of gestation). On the day before a urine collection, the participants received a reminder call to explain the urine collection procedure again. Participants were asked to discard their first urine specimen on the morning of collection and to collect all specimens for the next $24 \mathrm{~h}$. After all urine was collected, the urine volume was marked as a horizontal line on the 3 litre bottle with a felt-tipped marker. After the well-stoppered 3 litre bottle was shaken up and down at least ten times, a sample of the pooled urine was transferred to the $50 \mathrm{ml}$ plastic bottle using a dropper. These procedures were performed by the participants. A researcher received each $50 \mathrm{ml}$ plastic bottle with urine sample as well as the empty marked 3 litre bottle.

Each participant completed the questionnaire while waiting for an antenatal check-up at 19-23 weeks of gestation. Participants who did not have sufficient time to answer the questionnaires completed them after returning home and submitted them by mail within $7 \mathrm{~d}$. We resolved missing and unclear data directly when the questionnaires were submitted 
or by telephone interview. We reviewed the participants' medical charts to obtain information regarding their pregnancies.

This study was conducted according to the guidelines laid down in the Declaration of Helsinki and all procedures involving human subjects / patients were approved by the ethics committee of the university (no. 3197). Each participant received detailed information about the study protocol, and then provided written informed consent.

\section{Dietary assessment}

The DHQ was used for the dietary assessment of pregnant Japanese women in this study. The DHQ was designed to assess dietary intake over the previous month in the Japanese adult population ${ }^{(31-34)}$ and has been previously validated in pregnant Japanese women ${ }^{(26)}$. The DHQ-measured unadjusted protein and $\mathrm{K}$ intake levels in the second trimester were significantly correlated with the corresponding 24-h urinary levels $\left(r_{\mathrm{s}} 0.307 \text { and } r_{\mathrm{s}} 0.342 \text {, respectively }\right)^{(26)}$. The DHQ is a twenty-two-page structured questionnaire that measures the daily intakes of 150 foods and selected nutrients. Items were derived from primary data of the National Nutrition Survey of Japan and various Japanese recipe books for Japanese dishes ${ }^{(31)}$. Protein intake was calculated mainly from cereals, nuts and pulses, fish and shellfish, meat and eggs. $\mathrm{K}$ intake was calculated mainly from cereals, potatoes, nuts and pulses, vegetables, fruits, fish and shellfish, meat and eggs. Eight eating frequency responses were listed, ranging from 'more than twice per d' to 'almost never'. The following five portion size responses were listed: less than half of the standard portion size, $0 \cdot 7-0 \cdot 8$ times the standard portion size, standard portion size, $1 \cdot 2-1 \cdot 3$ times the standard portion size, and more than 1.5 times the standard portion size. The standard portion sizes were derived from several recipe books for Japanese dishes. For instance, the standard portion size of milk is shown as a cup of $150 \mathrm{ml}$. The DHQ also includes questions regarding general dietary behaviours such as seasoning preferences, and usual cooking methods for fish and shellfish, meat, eggs and vegetables. This information regarding general dietary behaviours was used for estimation of dietary intake of five seasonings such as sugar and soya sauce. Estimates of nutrient intakes were calculated from the consumption frequencies and portion sizes of the foods listed using an ad hoc computer algorithm developed for the $\mathrm{DHQ}^{(31-34)}$.

Pregnant women in their second trimester are recommended to have an additional energy intake of $1050 \mathrm{~kJ} / \mathrm{d}(250 \mathrm{kcal} / \mathrm{d})$ compared with non-pregnant women. Therefore, the recommended energy intakes are 7950-9200 kJ/d (1900-2200 kcal/d) for 20- to 29-year-old women and 8370-9410 kJ/d (2000$2250 \mathrm{kcal} / \mathrm{d}$ ) for 30 - to 49 -year-old women ${ }^{(35)}$. The values vary by the individual physical activity level. We excluded participants who reported an extremely unrealistic energy intake, such as small eaters due to severe nausea and vomiting during pregnancy; that is, we excluded women in whom the reported energy intake was less than half the energy requirement for the lowest physical activity category (3970 or $4180 \mathrm{~kJ} / \mathrm{d}$; 950 or $1000 \mathrm{kcal} / \mathrm{d}$ ) or more than 1.5 times the energy requirement for moderate physical activity $(13810$ or $14120 \mathrm{~kJ} / \mathrm{d} ; 3300$ or
$3375 \mathrm{kcal} / \mathrm{d}$ ) according to the 'Dietary Reference Intakes for Japanese ${ }^{\text {(35,36) }}$.

\section{Biological measurements}

A single 24-h urine collection was conducted for measurements of urea $\mathrm{N}$ and $\mathrm{K}$ levels. The urine samples were stored at $-80^{\circ} \mathrm{C}$ within $8 \mathrm{~h}$ of collection, until the analyses. Urinary urea $\mathrm{N}$ levels were measured by the urease-LEDH method using an Iatro-LQ UN (A) II instrument (Mitsubishi Kagaku Bio-Chemical Laboratories, Inc.). The urea $\mathrm{N}$ levels in the 24-h urine sample were used to estimate the amount of dietary protein. Urinary $\mathrm{K}$ levels were measured by ion-selective electrodes. These assays were conducted using an automated analyser (BM6050; JEOL) from Mitsubishi Kagaku Bio-Chemical Laboratories, Inc.

We excluded women who did not meet the following criterion for acceptable 24-h urine collection: $10 \cdot 8-25 \cdot 2 \mathrm{mg} / \mathrm{kg}$ of creatinine excretion divided by body weight ${ }^{(37)}$. Urinary creatinine excretion was measured by the enzyme method using an Iatro-LQ CRE (A) II instrument (Mitsubishi Kagaku Bio-Chemical Laboratories, Inc.).

\section{Anthropometric measurement}

The participants' weight was measured using a DC320 weight scale (Tanita Corp.) at the 19- to 23-week antenatal check-up. In this study, weight change during pregnancy refers to the difference between the weight at the check-up at 19-23 weeks of gestation and the pre-pregnancy weight ((weight at the check-up at 19-23 weeks of gestation) - (pre-pregnancy weight)).

\section{General questionnaires}

We obtained the following demographic and lifestyle information using a self-administered questionnaire: age, gestational age, educational level, height, pre-pregnancy weight, smoking habits during pregnancy, pregnancy-associated nausea and vomiting, dietary restrictions, habit of skipping meals, habit of making own meals, and regular supplement usage. Pre-pregnancy BMI was calculated from the self-reported prepregnancy weight and height. The participants were classified as being underweight (BMI $<18.5 \mathrm{~kg} / \mathrm{m}^{2}$ ), normal weight $\left(18.5 \leq \mathrm{BMI}<25.0 \mathrm{~kg} / \mathrm{m}^{2}\right)$ and overweight or obese (BMI $\geq 25.0 \mathrm{~kg} / \mathrm{m}^{2}$ ) based on the WHO criteria. We defined regularly skipping meals as forgoing meals including a staple food, such as rice or bread, two or more times per week. Likewise, regularly skipping breakfast was defined as forgoing breakfast including a staple food, two or more times per week.

We asked questions regarding the participants' attitudes toward gestational weight gain and whether they managed their weight gain to prevent pregnancy complications and difficult deliveries or to return to their pre-pregnancy weight soon after childbirth.

Questions regarding potential psychosocial factors related to dietary under-reporting included social desirability, social approval motivation, self-efficacy and the fetal health locus of control. Social desirability was assessed using the Japanese 
version of the Marlowe-Crowne Social Desirability Scale ${ }^{(38)}$. In the Japanese version, ten items were selected from the original thirty-three items, according to the Japanese cultural background ${ }^{(38,39)}$. We used five-point Likert scale responses ranging from 'disagree strongly' to 'agree strongly' (0-40 points), with higher scores indicating a higher level of social desirability. Cronbach's $\alpha$ in the present study was 0.715 .

Social approval motivation was assessed using the Japanese version of the Revised Martin-Larsen Approval Motivation Scale ${ }^{(40,41)}$. This scale consists of twenty items, answered using five-point Likert scale responses ranging from 'disagree strongly' to 'agree strongly' (20-100 points). Higher scores indicate a greater need for social approval. Cronbach's $\alpha$ in the present study was 0.737 .

Self-efficacy was assessed using the General Self-Efficacy Scale (GSES), the validity and reliability of which have been established $^{(42)}$. This scale consists of sixteen true-false questions divided into three subscales: positive attitude to activities (seven items; e.g. 'I tend to carry out my work with confidence'), anxiety about failure (five items; e.g. 'I often feel depressed when I recall past mistakes and bad experiences'), and social position of abilities (four items; e.g. 'I have better abilities than my friends'). Higher scores indicate a higher level of self-efficacy ( $0-16$ points). Cronbach's $\alpha$ in the present study was $0 \cdot 805$.

Fetal health locus of control reflects pregnant women's locus of control beliefs toward the health of their babies; this was assessed using the Japanese version of the Fetal Health Locus of Control Scale (FHLC). The validity and reliability of the FHLC have already been established ${ }^{(43,44)}$. The Japanese version of the FHLC consists of fifteen items categorised into internal, chance, and supernatural subscales, each containing five items. The internal subscale indicates that the well-being of a woman's fetus is principally under her own behavioural control. The chance subscale indicates that the well-being of a woman's fetus is chiefly due to fate or chance. The supernatural subscale indicates that the wellbeing of a woman's fetus is primarily influenced by the divine. Scores are calculated for each component, and higher scores reflect stronger beliefs in that particular locus of control for determining fetal health. In this study, we used only the internal subscale of the FHLC. Items are rated using a sixpoint Likert scale ranging from 'disagree strongly' to 'agree strongly' (5-30 points). Cronbach's $\alpha$ in the present study was $0 \cdot 884$.

\section{Identification of dietary under-reporters}

The reporting accuracy was calculated as the ratio of reported intake from the DHQ to the estimated intake based on the 24-h urinary excretion levels. Protein intake estimated from 24-h urinary excretion was calculated as (24-h urinary urea $\mathrm{N} \times 7.72) \mathrm{g}^{(45)}$ divided by 0.85 , assuming that $85 \%$ of the ingested protein is excreted in the urine at 23 weeks of gestation $^{(46)}$. $\mathrm{K}$ intake estimated from urinary excretion was calculated as the 24 -h urinary $\mathrm{K}$ level divided by 0.77 , assuming that $77 \%$ of the ingested $\mathrm{K}$ is excreted in the urine ${ }^{(47)}$. The $\mathrm{K}$ excretion rate for non-pregnant women was used, because the change associated with pregnancy is very small ${ }^{(48)}$. A reporting accuracy of $<1.0$ is theoretically considered as underreporting, while accuracies of $>1.0$ and 1.0 are defined as over-reporting and accurate reporting, respectively ${ }^{(49)}$. In the present study, under-reporting of protein and $\mathrm{K}$ was defined as the bottom $25 \%$ of the reporting accuracy based on a previous review ${ }^{(3)}$ that observed under-reporting in an average of $25 \%$ of non-pregnant women and other previous studies ${ }^{(4-16)}$. Herein, dietary under-reporters were defined as participants who under-reported both protein and $\mathrm{K}$ intake.

\section{Statistical analyses}

Multiple logistic regression analysis was performed to examine the factors related to dietary under-reporters. Before performing this analysis, Student's $t$ test, the Mann-Whitney $U$ test, the $\chi^{2}$ test, and Fisher's exact test were conducted to identify potential variables related to under-reporters. Variables with $P<0.20$ in the univariate analyses were selected as variables for the multiple logistic regression analysis. These variables were checked for multicollinearity. If the correlation coefficient of any two variables was greater than 0.50 or any two categorical variables were significantly correlated by the $\chi^{2}$ test, either variable was excluded from the model.

All statistical analyses were conducted using IBM SPSS Statistics for Windows, version 21.0 (IBM Japan). All statistical tests were two-sided and $P$ values $<0.05$ were considered statistically significant.

\section{Results}

A total of 398 pregnant women were recruited in the present study; $326(81.9 \%)$ provided written informed consent, answered the questionnaires and collected their urine. Of them, fifty-five were excluded from the analysis: thirty-one missed at least one urine collection, eight did not meet the creatinine criteria, seven had severely under-reported energy intakes, five dropped out, and four had missing data. Thus, data from 271 $(68.1 \%)$ healthy singleton pregnant women were analysed. No one met the criterion of dietary over-reporting.

The reporting accuracies of protein and $\mathrm{K}$ intakes were calculated as the ratios of reported dietary intake from the DHQ to the estimated dietary intake from 24-h urinary excretion levels (Table 1). The 25th percentiles of reporting accuracies were 0.77 for protein and 0.64 for $\mathrm{K}$. A total of sixtyseven pregnant women were found to under-report protein intake $(<0 \cdot 77)$, and sixty-seven women were found to underreport $\mathrm{K}$ intake $(<0 \cdot 64)$. Of the pregnant women, thirty-five $(12.9 \%)$ under-reported both protein and $\mathrm{K}$ intakes, and

Table 1. Reporting accuracies* of protein and potassium intakes ( $n$ 271) (Mean values and standard deviations; medians and interquartile ranges)

\begin{tabular}{lcccc}
\hline & Mean & SD & Median & Interquartile range \\
\hline Protein & 0.98 & 0.30 & 0.92 & $0.77-1.15$ \\
K & 0.89 & 0.36 & 0.82 & $0.64-1.06$ \\
\hline
\end{tabular}

${ }^{*}$ Reporting accuracy is the ratio of reported intake from the Diet History Questionnaire to the estimated intake based on 24-h urinary excretion levels. 
were identified as dietary under-reporters. Among the dietary under-reporters, four (11.4\%) were pre-pregnancy underweight (BMI $<18.5 \mathrm{~kg} / \mathrm{m}^{2}$ ), thirty $(85.7 \%)$ were of normal weight $\left(18.5 \leq \mathrm{BMI}<25.0 \mathrm{~kg} / \mathrm{m}^{2}\right)$ and one $(2.9 \%)$ was overweight $\left(B M I \geq 25 \cdot 0 \mathrm{~kg} / \mathrm{m}^{2}\right.$ ). No relationship between under-reporters and their pre-pregnancy BMI was found.

Table 2 summarises the participant characteristics. The mean age was 34.5 (sD 3.9 ) years, and $65.3 \%$ were primigravida. The rate of university graduates or above was $50.9 \%$. Of the participants, $29 \%$ had pregnancy-associated nausea and vomiting. Women with nausea and vomiting or who were overweight or obese had significantly lower gestational weight gain at 19-23 weeks of gestation.

The median (interquartile range) levels of reported dietary intake and 24-h urinary excretion are shown in Table 3. The daily intakes of total energy, protein and $\mathrm{K}$ were significantly lower in the under-reporters than in the normal reporters (median intake, 5979 v. $7707 \mathrm{~kJ} / \mathrm{d}(1429$ v. $1842 \mathrm{kcal} / \mathrm{d}$ ), 48.08 v. $64.30 \mathrm{~g} / \mathrm{d}$, and 1.66 v. $2.23 \mathrm{~g} / \mathrm{d}$, respectively). The protein and $\mathrm{K}$ intakes were significantly positively correlated with energy intake $(r 0.856, P<0.001$ and $r 0.783, P<$ $0 \cdot 001$, respectively). On the other hand, the urinary urea $\mathrm{N}$ and $\mathrm{K}$ levels were significantly higher in the under-reporters than in the normal reporters (median level, $7.46 v .6 .63 \mathrm{~g} / \mathrm{d}$, and $2.39 v .1 .78 \mathrm{~g} / \mathrm{d}$, respectively).

Multiple logistic regression analysis was conducted to explore the factors related to dietary under-reporters (Table 4). Based on the results of the univariate analyses, the following variables were included in the multiple logistic regression model: prepregnancy BMI, weight change during pregnancy, management of gestational weight gain with the aim to return to prepregnancy weight soon after childbirth, regularly skipping breakfast and the GSES score. The characteristics independently associated with dietary under-reporters during pregnancy were lower pre-pregnancy BMI (adjusted OR $(\mathrm{AOR})=0.81$; $P=0.041)$, lower gestational weight gain $(\mathrm{AOR}=0.82 ; P=$ 0.024 ), and management of gestational weight gain with the aim to return to their pre-pregnancy weight soon after childbirth (AOR $=2.99 ; P=0.009)$. Regularly skipping breakfast and the GSES score were not significantly correlated with dietary under-reporters, after controlling for the other variables.

\section{Discussion}

In the present study, we examined factors related to underreporters in a dietary assessment questionnaire among Japanese women during the second trimester of pregnancy. The characteristics associated with under-reporters, who were classified as both protein and $\mathrm{K}$ under-reporting, were lower pre-pregnancy BMI, lower gestational weight gain, and management of gestational weight gain with the aim to return to their pre-pregnancy weight soon after childbirth.

We sought to better understand dietary under-reporters by identifying under-reporting using 24-h urinary excretion of protein and $\mathrm{K}$. This method was based on previous studies that showed that under-reporting of protein and $\mathrm{K}$ intakes was strongly associated with under-reporting of energy intake $^{(29,30,50)}$. The cut-off points of under-reporting, defined as the bottom $25 \%$ of the reporting accuracy for each nutrient in the present study, were stricter than the theoretical figure of $1 \cdot 0$. Thus, the under-reporters identified in the present study were presumed to have severely under-reported their dietary intake.

Participants with lower pre-pregnancy BMI were more likely to under-report their dietary intake. This result differed from the results of previous studies of non-pregnant women in other countries, which reported that overweight and obese women tend to under-report their dietary intake owing to their desire for weight $\operatorname{loss}^{(1,4,5,8)}$. In contrast, a Japanese study ${ }^{(13)}$ reported that most dietary under-reporters among young non-pregnant women were relatively lean. Japan has a unique situation in that the rate of underweight women is higher and the rate of overweight and obese women is lower than the rates in other developed countries ${ }^{(51)}$. The rate of prepregnancy underweight women in our study (19\%) was far higher than those in other developed countries (3 and $2 \%$ in the USA and Portugal, respectively) ${ }^{(52,53)}$. Furthermore, young Japanese women are likely to desire weight loss and to perform unnecessary weight control, even though their BMI indicates that they are underweight or have normal weight ${ }^{(54,55)}$. Such cultural differences in the attitudes towards weight might have contributed to the opposite findings in the present study. Our results suggest that lower pre-pregnancy weight should be considered a risk factor for dietary underreporting in Japanese dietary surveys.

Dietary under-reporters had significantly lower gestational weight gain at 19-23 weeks of gestation. The lower gestational weight gain might have been partly due to severe nausea and vomiting during pregnancy because women with nausea and vomiting had significantly lower gestational weight gain at 19-23 weeks of gestation. However, if ingested foods were lost by vomiting, the reporting accuracy would be skewed towards over-reporting because the urinary excretion levels of nutrients would be lower than the ingested amounts. Thus, this opposite result is noteworthy. One possible explanation is that women who vomited after eating might not report the dietary intake, even if the foods they ate were partially absorbed. In addition, despite their efforts, participants with nausea and vomiting often feel that they do not have adequate dietary intake for themselves and their babies ${ }^{(56)}$. Therefore, a contrast between reality and desire might result in differences between true and perceived intakes, specifically in underestimation of the actual quantity consumed. Healthcare professionals should recognise the possible effects of severe nausea or vomiting on under-reporting when they assess selfreported dietary intake during pregnancy.

Moreover, dietary under-reporters were more likely to manage their gestational weight gain with the aim to return to their pre-pregnancy weight soon after childbirth. It is well known that excessive gestational weight gain contributes to postpartum weight retention ${ }^{(57)}$. Most of our participants had a desire to return to their pre-pregnancy weights, similar to the findings of another study of pregnant Japanese women (82 and $86 \%$, respectively) ${ }^{(25)}$. Management of gestational weight gain often leads to dietary restriction. The relationship between dietary restriction and under-reporting has been observed in 
Table 2. Characteristics of participants

(Mean values, standard deviations and ranges; numbers of participants and percentages)

\begin{tabular}{|c|c|c|c|c|c|c|c|c|c|c|}
\hline & \multicolumn{3}{|c|}{ All participants ( $n$ 271) } & \multicolumn{3}{|c|}{ Under-reporters ( $n$ 35) } & \multicolumn{3}{|c|}{ Normal reporters ( $n$ 236) } & \multirow[b]{2}{*}{$P^{*}$} \\
\hline & Mean & SD & Range & Mean & SD & Range & Mean & SD & Range & \\
\hline Age (years) & 34.5 & 3.9 & 23-44 & 34.6 & 3.6 & 29-44 & 34.4 & 4.0 & 23-44 & 0.783 \\
\hline Gestational age (weeks) & $20 \cdot 3$ & $1 \cdot 1$ & $19-23$ & 20.5 & $1 \cdot 3$ & $19-23$ & $20 \cdot 3$ & $1 \cdot 1$ & $19-23$ & 0.376 \\
\hline Parity: primigravida & & & & & & & & & & 1.000 \\
\hline$n$ & \multicolumn{3}{|c|}{177} & \multicolumn{2}{|c|}{23} & & \multicolumn{2}{|c|}{154} & & \\
\hline$\%$ & \multicolumn{2}{|c|}{$65 \cdot 3$} & & \multicolumn{2}{|c|}{65.7} & & \multicolumn{2}{|c|}{$65 \cdot 3$} & & \\
\hline \multicolumn{11}{|l|}{ Education level } \\
\hline $\begin{array}{l}\text { High school/junior or technical } \\
\text { college }\end{array}$ & & & & & & & & & & 0.250 \\
\hline$n$ & \multicolumn{2}{|c|}{133} & & \multicolumn{2}{|c|}{14} & & \multicolumn{2}{|c|}{119} & & \\
\hline$\%$ & $4 \varsigma$ & & & 40 & & & 50 & & & \\
\hline University or above & & & & & & & & & & \\
\hline$n$ & & & & 2 & & & 11 & & & \\
\hline$\%$ & & & & 60 & & & 49 & & & \\
\hline Working & & & & & & & & & & 0.202 \\
\hline$n$ & & & & 1 & & & 10 & & & \\
\hline$\%$ & & & & 34 & & & 45 & & & \\
\hline Height $(\mathrm{cm})$ & $158 \cdot 8$ & $5 \cdot 1$ & $147-172$ & 158.4 & $5 \cdot 1$ & $147-168$ & $158 \cdot 9$ & $5 \cdot 1$ & $147-172$ & 0.605 \\
\hline Pre-pregnancy BMI $\left(\mathrm{kg} / \mathrm{m}^{2}\right)$ & $20 \cdot 4$ & $2 \cdot 4$ & $16 \cdot 4-34 \cdot 4$ & $19 \cdot 8$ & $1 \cdot 7$ & $17 \cdot 1-26 \cdot 0$ & $20 \cdot 5$ & $2 \cdot 5$ & $16 \cdot 4-34 \cdot 4$ & 0.043 \\
\hline Underweight $\left(\mathrm{BMI}<18.5 \mathrm{~kg} / \mathrm{m}^{2}\right)$ & & & & & & & & & & 0.284 \\
\hline$n$ & & & & 2 & & & 4 & & & \\
\hline$\%$ & & & & 11 & & & 20 & & & \\
\hline $\begin{array}{l}\text { Normal weight } \\
\left(18.5 \leq \mathrm{BMl}<25.0 \mathrm{~kg} / \mathrm{m}^{2}\right)\end{array}$ & & & & & & & & & & \\
\hline$n$ & & & & 3 & & & 17 & & & \\
\hline$\%$ & & & & 85 & & & 73 & & & \\
\hline $\begin{array}{l}\text { Overweight or obese } \\
\left(B M I \geq 25.0 \mathrm{~kg} / \mathrm{m}^{2}\right)\end{array}$ & & & & & & & & & & \\
\hline$n$ & & & & 1 & & & 1 & & & \\
\hline$\%$ & & & & 2 & & & 6 & & & \\
\hline $\begin{array}{l}\text { Weight change during pregnancy } \\
(\mathrm{kg}) \dagger\end{array}$ & $2 \cdot 35$ & $2 \cdot 47$ & -8.7 to 10.4 & 1.69 & $2 \cdot 41$ & -3.7 to 5.9 & $2 \cdot 45$ & $2 \cdot 46$ & -8.7 to 10.4 & 0.087 \\
\hline $\begin{array}{l}\text { Management of gestational weight } \\
\text { gain with the aim to return to } \\
\text { pre-pregnancy weight soon after } \\
\text { childbirth }\end{array}$ & & & & & & & & & & 0.012 \\
\hline$n$ & & & & 1 & & & 3 & & & \\
\hline$\%$ & & & & 34 & & & 16 & & & \\
\hline Smoking during pregnancy & & & & & & & & & & 1.000 \\
\hline$n$ & & & & c & & & 1 & & & \\
\hline$\%$ & & & & 0 & & & 0 & & & \\
\hline $\begin{array}{l}\text { Pregnancy-associated nausea or } \\
\text { vomiting }\end{array}$ & & & & & & & & & & 0.265 \\
\hline$n$ & & & & 1 & & & 6 & & & \\
\hline$\%$ & & & & 37 & & & 28 & & & \\
\hline Regularly skipping mealsł & & & & & & & & & & 0.193 \\
\hline$n$ & & & & 1 & & & 9 & & & \\
\hline$\%$ & & & & 51 & & & 39 & & & \\
\hline Regularly skipping breakfastł & & & & & & & & & & 0.065 \\
\hline$n$ & & & & 1 & & & 7 & & & \\
\hline$\%$ & & & & 45 & & & 30 & & & \\
\hline Making own meal & & & & & & & & & & 1.000 \\
\hline$n$ & & & & 3 & & & 2 & & & \\
\hline$\%$ & & & & 91 & & & 90 & & & \\
\hline Regular supplement usage & & & & & & & & & & \\
\hline Folic acid supplements & & & & & & & & & & 0.670 \\
\hline$n$ & & & & 1 & & & 1 & & & \\
\hline$\%$ & & & & 54 & & & 50 & & & \\
\hline Multivitamin supplements & & & & & & & & & & 0.784 \\
\hline$n$ & & & & $\varepsilon$ & & & 5 & & & \\
\hline$\%$ & & & & 22 & & & 25 & & & \\
\hline Fe supplements & & & & & & & & & & 0.808 \\
\hline$n$ & & & & $s$ & & & 5 & & & \\
\hline$\%$ & & & & 25 & & & 23 & & & \\
\hline MCSD (score)§ & $28 \cdot 9$ & 4.8 & $11-40$ & $28 \cdot 5$ & 4.5 & $17-36$ & $29 \cdot 0$ & 4.9 & $11-40$ & 0.519 \\
\hline MLAM (score)\| & $56 \cdot 8$ & $7 \cdot 2$ & $5-75$ & $56 \cdot 2$ & $7 \cdot 0$ & $40-73$ & $56 \cdot 9$ & $7 \cdot 3$ & $5-75$ & 0.612 \\
\hline
\end{tabular}


Table 2. Continued

\begin{tabular}{|c|c|c|c|c|c|c|c|c|c|c|}
\hline & \multicolumn{3}{|c|}{ All participants ( $n$ 271) } & \multicolumn{3}{|c|}{ Under-reporters (n 35) } & \multicolumn{3}{|c|}{ Normal reporters ( $n$ 236) } & \multirow[b]{2}{*}{$P^{\star}$} \\
\hline & Mean & SD & Range & Mean & SD & Range & Mean & SD & Range & \\
\hline GSES (score)ף & 8.7 & 3.7 & $0-16$ & $7 \cdot 7$ & 3.3 & $2-15$ & 8.8 & 3.7 & $0-16$ & 0.080 \\
\hline FHLC, internal subscale (score) ${ }^{\star *}$ & $27 \cdot 3$ & 2.9 & $16-30$ & $27 \cdot 0$ & 3.0 & 20-30 & $27 \cdot 4$ & $2 \cdot 9$ & $16-30$ & 0.495 \\
\hline
\end{tabular}

MCSD, Marlowe-Crowne Social Desirability Scale; MLAM, Revised Martin-Larsen Approval Motivation Scale; GSES, General Self-Efficacy Scale; FHLC, Fetal Health Locus of Control Scale.

* Student's $t$ test, $\chi^{2}$ test or Fisher's exact test.

† Weight change during pregnancy refers to the difference between weight at the check-up at 19-23 weeks of gestation and the pre-pregnancy weight: ((weight at the check-up at 19-23 weeks of gestation) - (pre-pregnancy weight)).

‡ Regularly skipping meals (breakfast) was defined as forgoing meals (breakfast) including a staple food, such as rice or bread, two or more times per week.

$\S$ Higher scores on the MCSD indicate a higher level of social desirability (0-40 points).

$\|$ Higher scores on the MLAM indicate a greater need for social approval (20-100 points).

1) Higher scores on the GSES indicate a higher level of self-efficacy (0-16 points).

** Higher scores on the FHLC reflect stronger beliefs in that particular locus of control for determining fetal health. The internal subscale indicates that the well-being of a woman's fetus is principally under her own behavioural control (5-30 points).

non-pregnant populations ${ }^{(58,59)}$. On the other hand, managing weight gain for the prevention of pregnancy complications and difficult deliveries was not associated with dietary underreporting in the present study. Pregnancy complications and difficult deliveries may result from either too little or excessive weight gain; however, only excessive weight gain is of concern in order to return to pre-pregnancy weight after childbirth. Thus, management of weight gain with the aim to return to their pre-pregnancy weight soon after childbirth might be an alternative indicator of dietary restriction during pregnancy.

Regularly skipping breakfast and the GSES score were not significantly correlated with dietary under-reporters, although they were included in the multiple regression model based on the results of the univariate analyses. Further research on the relationships between these variables and dietary underreporting is required. In particular, dietary-specific self-efficacy might directly influence dietary reporting accuracy, although we could not assess this relationship due to the lack of a validated dietary-specific self-efficacy scale for pregnant women.

In contrast to previous studies of non-pregnant women, social desirability and social approval motivation were not associated with dietary under-reporting during pregnancy ${ }^{(19,60)}$. The internal subscale of the FHLC was also not associated with the reporting accuracy of dietary intake, although we hypothesised that pregnant women with strong beliefs that their healthy lifestyles positively affect the well-being of their fetuses might misreport dietary intake by choosing to give socially desirable responses. In the prenatal period, however, socially desirable dietary habits vary among individuals, because some consider eating a lot of vegetables to be a socially desirable habit, while others consider smaller energy intake to be a socially desirable habit. Even if social desirability or social approval motivation affected the reporting accuracy, individual differences in the perceived social desirability of healthy diets during pregnancy would have attenuated the effect.

The present study had several limitations. First, the participant characteristics may have been biased because the research was conducted at a single university hospital in an urban area. Further, the mean age of the participants in this study was slightly higher than that of the participants in national reports $(34.5 v .31 .7 \text { years })^{(61)}$. Although the dietary intakes of our participants were equivalent to in similar reports, differences in the demographic characteristics might potentially have affected the dietary intake. Second, our sample size was relatively small. Especially, only thirty-five under-reporters were identified. Thus, the results should be interpreted cautiously. Further large-scale studies are required to confirm the results of the present study. Third, in consideration of feasibility, a single 24-h urine collection was conducted although multiple 24-h urine collections are recommended to alleviate the influence

Table 3. Nutrient intakes estimated from the self-administered Diet History Questionnaire and 24-h urinary excretion levels (Medians and interquartile ranges)

\begin{tabular}{|c|c|c|c|c|c|c|c|}
\hline & \multicolumn{2}{|c|}{ All participants ( $n$ 271) } & \multicolumn{2}{|c|}{ Under-reporters (n 35) } & \multicolumn{2}{|c|}{ Normal reporters ( $n$ 236) } & \multirow[b]{2}{*}{$P^{*}$} \\
\hline & Median & Interquartile range & Median & Interquartile range & Median & Interquartile range & \\
\hline \multicolumn{8}{|l|}{ Nutrient intakes } \\
\hline \multicolumn{8}{|l|}{ Energy } \\
\hline $\mathrm{kJ} / \mathrm{d}$ & 7460 & $6431-8640$ & 5979 & $5230-6456$ & 7707 & $6581-8786$ & $<0.001$ \\
\hline $\mathrm{kcal} / \mathrm{d}$ & 1783 & $1537-2065$ & 1429 & $1250-1543$ & 1842 & $1573-2100$ & $<0.001$ \\
\hline Protein $(\mathrm{g} / \mathrm{d})$ & $61 \cdot 70$ & $53.05-74.19$ & 48.08 & $42 \cdot 68-56.07$ & $64 \cdot 30$ & $55 \cdot 33-76 \cdot 16$ & $<0.001$ \\
\hline$K(g / d)$ & $2 \cdot 16$ & $1.73-2.59$ & 1.66 & $1.38-1.94$ & $2 \cdot 23$ & $1.79-2.73$ & $<0.001$ \\
\hline \multicolumn{8}{|l|}{ Urinary markers } \\
\hline $24-\mathrm{h}$ total urine volume $(\mathrm{ml} / \mathrm{d})$ & 1320 & $1060-1690$ & 1330 & $1060-1800$ & 1315 & $1046-1690$ & 0.701 \\
\hline Urea $N(g / d)$ & 6.77 & $5.66-7.90$ & 7.46 & $6.60-8.78$ & 6.63 & $5 \cdot 52-7.78$ & 0.003 \\
\hline$K(g / d)$ & 1.81 & $1.44-2.26$ & 2.39 & $1 \cdot 72-2 \cdot 72$ & 1.78 & $1.43-2.17$ & $<0.001$ \\
\hline
\end{tabular}

${ }^{*}$ Mann-Whitney $U$ test. 
Table 4. Factors related to dietary under-reporting $(n 271)^{\star}$ (Odds ratios and $95 \%$ confidence intervals)

\begin{tabular}{|c|c|c|c|c|c|c|}
\hline & Crude OR & $95 \% \mathrm{Cl}$ & $P$ & Adjusted OR & $95 \% \mathrm{Cl}$ & $P$ \\
\hline Pre-pregnancy BMI (kg/m²) & 0.87 & $0.73,1.03$ & 0.111 & 0.81 & $0.67,0.99$ & 0.041 \\
\hline Weight change during pregnancy $+(\mathrm{kg})$ & 0.89 & $0.77,1.02$ & 0.089 & 0.82 & $0.70,0.97$ & 0.024 \\
\hline $\begin{array}{l}\text { Management of gestational weight gain with the aim to return } \\
\text { to pre-pregnancy weight soon after childbirth }(\text { yes }=1 ; n o=0)\end{array}$ & 2.64 & $1 \cdot 21,5 \cdot 74$ & 0.015 & 2.99 & $1 \cdot 31,6 \cdot 85$ & 0.009 \\
\hline Regularly skipping breakfastł (yes $=1 ;$ no $=0)$ & 1.96 & $0.95,4.02$ & 0.068 & 1.88 & $0.89,3.97$ & 0.097 \\
\hline GSES§ (score) & 0.92 & $0.86,1.01$ & 0.082 & 0.96 & $0.86,1.06$ & 0.385 \\
\hline
\end{tabular}

GSES, General Self-Efficacy Scale.

*Multiple logistic regression analysis. Each variable in the table was adjusted for all other variables in the table. The dependent variable is under-reporters (yes $=1 ;$ no $=0$ ). Under-reporters are participants with both protein and K under-reporting ( $n$ 35). 'Pre-pregnancy BMl', 'weight change during pregnancy' and 'GSES' are continuous variables. 'Management of gestational weight gain with the aim to return to pre-pregnancy weight soon after childbirth' and 'regularly skipping breakfast' are categorical variables (yes $=1$; no $=0$ ).

† Weight change during pregnancy refers to the difference between weight at the check-up at 19-23 weeks of gestation and the pre-pregnancy weight: ((weight at the check-up at 19-23 weeks of gestation) - (pre-pregnancy weight)).

‡ Regularly skipping breakfast was defined as forgoing breakfast including a staple food, such as rice or bread, two or more times per week.

$\S$ Higher scores of the GSES indicate a higher level of self-efficacy (0-16 points).

of day-to-day variations ${ }^{(62)}$. However, the excretion levels of protein and $\mathrm{K}$ would probably reflect habitual intake, because they have few changes by the day ${ }^{(48,63)}$. Fourth, the present study used the DHQ to collect self-reported dietary data. The DHQ includes 150 selected foods and beverage items. These 150 items were chosen based on foods that Japanese people typically eat. Thus, we consider that the DHQ can estimate the dietary intake in most participants. However, if the participants prefer to eat uncommon foods that are not included in the DHQ, the estimation of dietary intake might be insufficient. Fifth, we set up relative cut-off points of under-reporting. We speculated that the under-reporters identified in our study under-reported dietary intake heavily, because the cut-off point was a strict criterion. However, the present results might be partially affected by the chosen cut-off value. Sixth, the pre-pregnancy weights used in the present study were self-reported. Healthcare professionals always ask pregnant women about their pre-pregnancy weight at the first check-up of pregnancy and describe the values in the medical charts and the maternal and child health handbooks. Accordingly, we consider that the self-reported values (same as in the medical charts and the maternal and child health handbooks) are fairly reliable.

In conclusion, the findings of the present study revealed the following characteristics of dietary under-reporters during pregnancy in Japan: lower pre-pregnancy BMI, lower gestational weight gain, and management of gestational weight gain with the aim to return to pre-pregnancy weight soon after childbirth. Healthcare professionals should consider the effects of pregnancy-specific weight-related variables on dietary under-reporting when assessing the dietary intake of pregnant Japanese women. However, the sample size of the present study was small. Thus, larger studies are required to confirm the factors related to dietary under-reporting during pregnancy.

\section{Acknowledgements}

The authors are deeply grateful to the participants and the hospital staff for their cooperation. The present study was supported by the Institute for Food and Health Science, Yazuya
Co. Ltd, 2009 and Fumiko Yamaji professional nursing education, 2011.

M. S., M. M. and M. H. planned the study and collected the data. M. S. conducted data analyses and drafted the manuscript. All authors made substantial contributions to the interpretation of the results and approved the final paper.

The authors declare that they have no conflicts of interest.

\section{References}

1. Johansson L, Solvoll K, Bjørneboe GE, et al. (1998) Under- and overreporting of energy intake related to weight status and lifestyle in a nationwide sample. Am J Clin Nutr 68, 266-274.

2. Yannakoulia M, Panagiotakos DB, Pitsavos C, et al. (2007) Low energy reporting related to lifestyle, clinical, and psychosocial factors in a randomly selected population sample of Greek adults: the ATTICA Study. J Am Coll Nutr 26, 327-333.

3. Black AE, Goldberg GR, Jebb SA, et al. (1991) Critical evaluation of energy intake data using fundamental principles of energy physiology: 2. Evaluating the results of published surveys. Eur J Clin Nutr 45, 583-599.

4. Winkvist A, Persson V \& Hartini TN (2002) Underreporting of energy intake is less common among pregnant women in Indonesia. Public Health Nutr 5, 523-529.

5. Nowicki E, Siega-Riz AM, Herring A, et al. (2011) Predictors of measurement error in energy intake during pregnancy. $A m J$ Epidemiol 173, 560-568.

6. McGowan CA \& McAuliffe FM (2012) Maternal nutrient intakes and levels of energy underreporting during early pregnancy. Eur J Clin Nutr 66, 906-913.

7. Hébert JR, Clemow L, Pbert L, et al. (1995) Social desirability bias in dietary self-report may compromise the validity of dietary intake measures. Int J Epidemiol 24, 389-398.

8. Lafay L, Basdevant A, Charles MA, et al. (1997) Determinants and nature of dietary underreporting in a free-living population: the Fleurbaix Laventie Ville Santé (FLVS) Study. Int J Obes Relat Metab Disord 21, 567-573.

9. Briefel RR, Sempos CT, McDowell MA, et al. (1997) Dietary methods research in the third National Health and Nutrition Examination Survey: underreporting of energy intake. Am J Clin Nutr 65, 1203S-1209S.

10. Taren DL, Tobar M, Hill A, et al. (1999) The association of energy intake bias with psychological scores of women. Eur J Clin Nutr 53, $570-578$.

11. Scagliusi FB, Polacow VO, Artioli GG, et al. (2003) Selective underreporting of energy intake in women: magnitude, determinants, and effect of training. J Am Diet Assoc 103, 1306-1313. 
12. Tooze JA, Subar AF, Thompson FE, et al. (2004) Psychosocial predictors of energy underreporting in a large doubly labeled water study. Am J Clin Nutr 79, 795-804.

13. Okubo H \& Sasaki S (2004) Underreporting of energy intake among Japanese women aged 18-20 years and its association with reported nutrient and food group intakes. Public Health Nutr 7, 911-917.

14. Okubo H, Sasaki S, Hirota N, et al. (2006) The influence of age and body mass index on relative accuracy of energy intake among Japanese adults. Public Health Nutr 9, 651-657.

15. Okubo H, Sasaki S, Rafamantanantsoa HH, et al. (2008) Validation of self-reported energy intake by a self-administered diet history questionnaire using the doubly labeled water method in 140 Japanese adults. Eur J Clin Nutr 62, 1343-1350.

16. Murakami K, Sasaki S, Okubo H, et al. (2012) Characteristics of under- and over-reporters of energy intake among young Japanese women. J Nutr Sci Vitaminol 58, 253-262.

17. Stallone DD, Brunner EJ, Bingham SA, et al. (1997) Dietary assessment in Whitehall II: the influence of reporting bias on apparent socioeconomic variation in nutrient intakes. Eur J Clin Nutr 51, 815-825.

18. Pomerleau J, Ostbye T \& Bright-See E (1999) Potential underreporting of energy intake in the Ontario Health Survey and its relationship with nutrient and food intakes. Eur J Epidemiol 15, 553-557.

19. Horner NK, Patterson RE, Neuhouser ML, et al. (2002) Participant characteristics associated with errors in self-reported energy intake from the Women's Health Initiative food-frequency questionnaire. Am J Clin Nutr 76, 766-773.

20. Voss S, Kroke A, Klipstein-Grobusch K, et al. (1997) Obesity as a major determinant of underreporting in a self-administered food frequency questionnaire: results from the EPIC-Potsdam Study. $Z$ Ernabrungswiss 36, 229-236.

21. Samaras K, Kelly PJ \& Campbell LV (1999) Dietary underreporting is prevalent in middle-aged British women and is not related to adiposity (percentage body fat). Int J Obes Relat Metab Disord 23, 881-888.

22. Kretsch MJ, Fong AK \& Green MW (1999) Behavioral and body size correlates of energy intake underreporting by obese and normal-weight women. J Am Diet Assoc 99, 300-308.

23. Lanctot JQ, Klesges RC, Stockton MB, et al. (2008) Prevalence and characteristics of energy underreporting in African-American girls. Obesity 16, 1407-1412.

24. Walker LO, Cooney AT \& Riggs MW (1999) Psychosocial and demographic factors related to health behaviors in the 1st trimester. J Obstet Gynecol Neonatal Nurs 28, 606-614.

25. Takimoto H, Mitsuishi C \& Kato N (2011) Attitudes toward pregnancy related changes and self-judged dieting behavior. Asia Pac J Clin Nutr 20, 212-219.

26. Shiraishi M, Haruna M, Matsuzaki M, et al. (2017) Availability of two self-administered diet history questionnaires for pregnant Japanese women: a validation study using 24-hour urinary markers. J Epidemiol 27, 172-179.

27. Ainslie P, Reilly T \& Westerterp K (2003) Estimating human energy expenditure: a review of techniques with particular reference to doubly labelled water. Sports Med 33, 683-698.

28. Goldberg GR, Prentice AM, Coward WA, et al. (1993) Longitudinal assessment of energy expenditure in pregnancy by the doubly labeled water method. Am J Clin Nutr 57, 494-505.

29. Macdiarmid J \& Blundell J (1998) Assessing dietary intake: who, what and why of under-reporting. Nutr Res Rev 11, 231-253.

30. Murakami K, Sasaki S, Takahashi Y, et al. (2008) Misreporting of dietary energy, protein, potassium and sodium in relation to body mass index in young Japanese women. Eur J Clin Nutr 62, 111-118.

31. Sasaki S, Yanagibori R \& Amano K (1998) Self-administered diet history questionnaire developed for health education: a relative validation of the test-version by comparison with 3-day diet record in women. J Epidemiol 8, 203-215.

32. Sasaki S, Yanagibori R \& Amano K (1998) Validity of a selfadministered diet history questionnaire for assessment of sodium and potassium: comparison with single 24-hour urinary excretion. Jpn Circ J 62, 431-435.

33. Sasaki S, Ushio F, Amano K, et al. (2000) Serum biomarker-based validation of a self-administered diet history questionnaire for Japanese subjects. J Nutr Sci Vitaminol 46, 285-296.

34. Kobayashi S, Honda S, Murakami K, et al. (2012) Both comprehensive and brief self-administered diet history questionnaires satisfactorily rank nutrient intakes in Japanese adults. J Epidemiol 22, 151-159.

35. Ministry of Health, Labor and Welfare (2009) Dietary Reference Intakes for Japanese, 2010, presented by the Ministry of Health, Labor, May 29, 2009. http://www.mhlw.go.jp/shingi/2009/05/ s0529-4.html (accessed August 2017).

36. Sasaki S, Katagiri A, Tsuji T, et al. (2003) Self-reported rate of eating correlates with body mass index in 18-y-old Japanese women. Int $K$ Obes Relat Metab Disord 27, 1405-1410.

37. Cardiovascular Disease and Alimentary Comparison (CARDIAC) Study (1986) Shimane/Geneva: CARDIAC Study Protocol and Manual of Operations. Geneva: WHO Collaborating Center on Primary Prevention of Cardiovascular Diseases, and Cardiovascular Disease Unit.

38. Kitamura T \& Suzuki T (1986) Japanese version of social desirability scale (article in Japanese). Jpn J Soc Psychiatry 9, 173-180.

39. Crowne DP \& Marlowe D (1960) A new scale of social desirability independent of psychopathology. J Consul Psychol 24, 341-354.

40. Martin HJ (1984) A revised measure of approval motivation and its relationship to social desirability. J Pers Assess 48, 508-519.

41. Ueda S \& Yoshimori M (1991) An attempt to make the Japanese version of the Martin-Larsen Approval Motivation Scale. In Annual Report of Studies of Department of Education, Hiroshima University, vol. 39, pp. 151-156 (in Japanese).

42. Sakano Y \& Tohjoh M (1986) The General Self-Efficacy Scale (GSES): scale development and validation (article in Japanese). Jpn J. Behav Ther 12, 73-82.

43. Labs SM \& Wurtele SK (1986) Fetal Health Locus of Control Scale; development and validation. J Consult Clin Psychol 54, 814-819.

44. Manabe E, Hayashi E, Seto M, et al. (2001) An attempt to make the Japanese version of the Fetal Health Locus of Control Scale (article in Japanese). Quality Nursing 7, 417-425.

45. Bingham SA \& Cummings JH (1985) Urine nitrogen as an independent validatory measure of dietary intake: a study of nitrogen balance in individuals consuming their normal diet. Am J Clin Nutr 42, 1276-1289.

46. Mojtahedi M, de Groot LC, Boekholt HA, et al. (2002) Nitrogen balance of healthy Dutch women before and during pregnancy. Am J Clin Nutr 75, 1078-1083.

47. Tasevska N, Runswick SA \& Bingham SA (2006) Urinary potassium is as reliable as urinary nitrogen for use as a recovery biomarker in dietary studies of free living individuals. J Nutr 136, 1334-1340.

48. Hytten FE \& Leitch I (1971) Dietary requirements and dietary intake. In The Physiology of Human Pregnancy, pp. 409-439 [F Hytten and I Leitch, editors]. Oxford: Blackwell Scientific Publications.

49. Zhang J, Temme EH, Sasaki S, et al. (2000) Under- and overreporting of energy intake using urinary cations as biomarkers: relation to body mass index. Am J Epidemiol 152, 453-462.

50. Black AE, Welch AA \& Bingham SA (2000) Validation of dietary intakes measured by diet history against $24 \mathrm{~h}$ urinary nitrogen excretion and energy expenditure measured by the doubly-labelled water method in middle-aged women. Br J Nutr 83, 341-354.

51. Yates A, Edman J \& Aruguete M (2004) Ethnic differences in BMI and body/self-dissatisfaction among Whites, Asian subgroups, Pacific Islanders, and African-Americans. J Adolesc Health 34, 300-307.

52. Pinto E, Severo M, Correia S, et al. (2010) Validity and reproducibility of a semi-quantitative food frequency questionnaire for use among Portuguese pregnant women. Matern Child Nutr 6, 105-119.

53. Kosa JL, Guendelman S, Pearl M, et al. (2011) The association between pre-pregnancy BMI and preterm delivery in a diverse 
southern California population of working women. Matern Child Health J 15, 772-781.

54. Hayashi F, Takimoto H, Yoshita K, et al. (2006) Perceived body size and desire for thinness of young Japanese women: a populationbased survey. Br J Nutr 96, 1154-1162.

55. Sugawara A, Saito K, Sato M, et al. (2009) Thinness in Japanese young women. Epidemiology 20, 464-465.

56. O'Brien B \& Naber S (1992) Nausea and vomiting during pregnancy: effects on the quality of women's lives. Birth 19, 138-143.

57. Lyu LC, Lo CC, Chen HF, et al. (2009) A prospective study of dietary intakes and influential factors from pregnancy to postpartum on maternal weight retention in Taipei, Taiwan. BrJ Nutr 102, 1828-1837.

58. Bathalon GP, Tucker KL, Hays NP, et al. (2000) Psychological measures of eating behavior and the accuracy of 3 common dietary assessment methods in healthy postmenopausal women. Am J Clin Nutr 71, 739-745.
59. Rennie KL, Siervo M \& Jebb SA (2006) Can self-reported dieting and dietary restraint identify underreporters of energy intake in dietary surveys? J Am Diet Assoc 106, 1667-1672.

60. Hébert JR, Peterson KE, Hurley TG, et al. (2001) The effect of social desirability trait on self-reported dietary measures among multiethnic female health center employees. Ann Epidemiol 11, 417-427.

61. Ministry of Health, Labor and Welfare (2015) Vital Statistics. http://www.e-stat.go.jp/SG1/estat/List.do?lid=000001137964 (accessed August 2017).

62. Rand WM, Scrimshaw NS \& Young VR (1981) Conventional long term nitrogen-balance studies for protein quality evaluation in adults: rationale and limitations. In Protein Quality in Humans: Assessment and in Vitro Estimation, pp. 59-97 [CE Bodwell, JS Atkins and DT Hopkins, editors]. Westport, CT: AVI Publishing Co., Inc.

63. Nakago S, Ueda Y, Takeuchi K, et al. (2002) Implication of maternal nitrogen balance in the regulation of circulating levels of insulinlike growth factor-I in human pregnancy. Endorr J 49, 299-305. 